\section{Comunicación política: caja de herramientas}

\section{Political communication: toolbox}

Fechas | En edición: 19/08/2019 - Publicación final: 01/01/2020

\section{Rubén RIVAS-DE-ROCA}

Universidad de Sevilla. España. rrivasderoca@us.es

\section{Comunicación política: caja de herramientas}

Enrique GIL CALVO.

Madrid: Los Libros de la Catarata, 2018.

240 páginas

ISBN: 978-84-9097-554-1

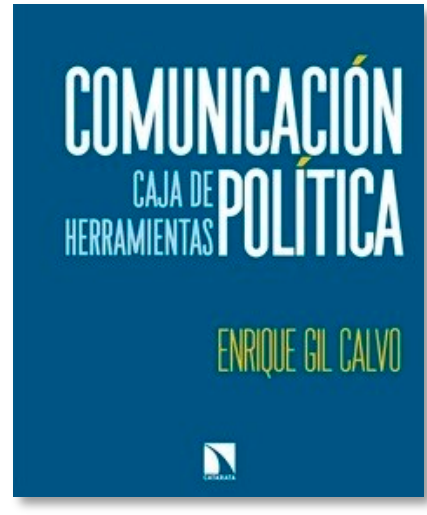

\section{Resumen}

El libro Comunicación política: caja de herramientas expone el valor de la comunicación en las actuales democracias representativas. El autor realiza una revisión detallada sobre los distintos paradigmas que han caracterizado la relación entre comunicación y política. Además, esta investigación académica se acompaña de una explicación pormenorizada de las principales herramientas comunicativas con las que cuentan los asesores electorales, instrumentos que son objeto de reflexión crítica.

\section{Palabras clave}

Comunicación política; Campañas electorales; Democracia de audiencias; Opinión pública

\begin{abstract}
The book Political Communication: toolbox exposes the value of communication in current representative democracies. The author makes a detailed review of the different paradigms that have characterized the relationship between communication and politics along the history. In addition, this academic research is supported by a detailed explanation of the main tools in the communication field available for professionals like spin-doctors. These instruments are also subject to critical reflection from an academic approach.
\end{abstract}

\section{Keywords}

Political communication; Electoral campaigns; Audience democracy; Public opinion 
El prestigioso catedrático emérito Gil Calvo lleva a cabo en su libro Comunicación política: caja de herramientas un repaso a la dimensión que la comunicación política posee en las democracias, siguiendo la forma de ensayo sociológico, apoyado a su vez en un minucioso trabajo de campo sobre el área de comunicación. La sociedad digital, y en particular los new media encarnados por las redes sociales, han trasladado la mediatización de la política a una nueva dimensión, en la que el exceso de eficacia de la comunicación política ha generado la expansión de fuerzas centrífugas a las democracias tanto en Europa como en Estados Unidos.

En un contexto de obligada reflexividad sobre la relación entre comunicación y poder, derivada del auge de los populismos, el autor brinda una aproximación que aspira a trazar la historia de la comunicación política, ofreciendo asimismo un catálogo de las herramientas más frecuentes en este sector. La obra se estructura en una introducción y 5 capítulos: la naturaleza de la comunicación política, principales paradigmas, genealogía del discurso público, caja de herramientas y la lucha mediática por el poder.

El autor comienza remitiendo a la intrínseca relación entre comunicación y política, que aparece por primera vez definida en la época del Antigua Grecia. La voluntad de acaparar el poder, ya sea mediante fórmulas protodemocráticas o autoritarias, va a requerir el empleo de prácticas comunicativas efectivas. No obstante, es a finales del siglo XIX, con la consolidación de emergentes democracias representativas y la aparición de los medios informativos de masas, cuando la relación entre comunicación y política alcance grandes cuotas de relevancia. Este tema se convierte en objeto de estudio en el siglo XX, con los distintos paradigmas que Gil Calvo recoge en el capítulo segundo. De un primer momento en el que se concede una extraordinaria capacidad de influencia a los medios (teoría de la aguja hipodérmica), fruto de la corriente psicológica del conductismo, se pasa a la aproximación de los efectos limitados, para posteriormente configurar un punto intermedio de la mano de la teoría de la agenda-setting. Este influyente concepto aportado por McCombs y Shaw, sumados a los populares framing y priming, en lo que a construcción social de la realidad mediada se refiere, son empleados por el autor para elaborar el marco teórico.

El estado de la cuestión efectuado resulta clásico, pero completo para que el lector pueda entender de una forma documentada y compresiva las distintas aproximaciones realizadas por la academia al estudio de la relación entre comunicación y política. Para ello se cuenta con una abundante bibliografía. El libro alude también a cómo el desarrollo de la comunicación política ha trascendido del ámbito de las campañas electorales, algo motivado por la aparición del llamado "partido de masas" (catch-all party), caracterizado por su desideologización. Esto imbrica con el concepto de democracia de audiencias formulado por Manin en 1998, por el cual los elementos representativos y programáticos pierden peso frente a una disputa política que tiene lugar en la esfera mediática.

La mediatización de la política se agudiza por la emergencia de los news media vinculados a la Red (Facebook, Twitter, Instagram, etc.), que brindan al público un contacto con la clase dirigente más horizontal que el proporcionado por los clásicos mass media (prensa y radiotelevisión). A través de estos canales, el marketing político hace uso de una serie herramientas retóricas, de las que el autor da cuenta profusamente. Las estrategias comunicativas más populares recabadas por este libro son el storytelling, entendido como la construcción narrativa de un relato favorable al político de turno; el framing, consistente en un encuadre social que lleva a interpretar la realidad de una determinada manera, estableciendo el campo de juego simbólico; y las actuaciones políticas, que aglutinan desde la gestión de acontecimientos mediáticos a la tradicional propaganda y los efectos cognitivos de estas expresiones performativas.

En el último capítulo, Gil Calvo reflexiona de manera crítica sobre cómo la lucha por el poder se dilucida en un espacio mediatizado. La mediatización de la política, o en su caso la politización de lo mediático, constituyen una prueba del éxito de la comunicación política, cuyo exceso de eficacia podría ahondar en las crisis de representación que sufren numerosas democracias a lo largo del globo. Los actores políticos ya no buscan solo un golpe de efecto que movilice el sentido del voto a su favor, sino conseguir un respaldo duradero de la ciudadanía mediante la adhesión a unos ideales. Para lograr este nivel de implicación se aplica una polarización al eje político, que en palabras del autor se ha producido en los casos del procés catalán, el Brexit o la victoria de Trump en Estados Unidos.

En resumen, la obra aquí reseñada supone una excelente revisión práctica de la evolución y las posibilidades de la comunicación política, que se enfrenta hoy en día a la tesitura de servir como herramienta a movimientos populistas. El contenido de este libro se halla muy ligado a la actualidad, con ejemplos prácticos que remiten tanto a España, con la dimisión de Cristina Cifuentes en 2018, como a otros países que experimentan interesantes procesos de comunicación política. Esta conjunción entre actualidad y sistematización académica hace que su contenido sea de máximo interés tanto para profesionales como para investigadores. Sin embargo, se echa en falta una cierta contextualización de la 
comunicación política en el marco de los sistemas mediáticos comparados, una aproximación muy aceptada para el estudio de la relación entre comunicación y política. La referencia a estos sistemas habría permitido valorar los elementos culturales e históricos que afectan al ámbito informativo en el plano regional.

En cualquier caso, el libro presenta un nivel de detalle excelente, esbozando una caja de herramientas retóricas muy exhaustiva, que se complementa con un marco teórico que debe ser tenido en cuenta por los futuros investigadores de la materia. El autor no deja además pasar la oportunidad de realizar interesantes reflexiones sobre el vínculo entre comunicación y política en nuestros tiempos, donde el exceso de eficacia parece haber convertido las estrategias comunicativas en armas al servicio de la polarización. Sin duda, esta situación obliga a repensar el sentido que la comunicación política debe tener en los próximos años, para lo cual es imprescindible contar con obras tan sistemáticas y críticas como la elaborada por Gil Calvo. 